\title{
Do literário ao fílmico: "A Vida Invisível" e a universalização do discurso a partir do uso do melodrama
}

\section{From literature to film: "The Invisible Life" and the universalization of the discourse through the use of melodrama}

\section{Laís Rodrigues}

Universidade Federal de São Carlos. Departamento de Artes e Comunicação.

\section{RESUMO}

A partir do estudo comparativo entre o filme "A Vida Invisíve" e o livro que inspira o roteiro, este artigo tem como objetivo entender as nuances da construção narrativa de ambos, buscando se aprofundar na utilização da estrutura do subgênero melodrama para se transpor a produção literária em cinematográfica, e os possíveis efeitos políticos deste uso.

PALAVRAS-CHAVE: melodrama, cinema brasileiro, cinema contemporâneo, literatura, representação feminina.

\section{ABSTRACT}

From a comparative study between the movie "The Invisible Life" and the book from which the screenplay was adapted, this article aims to understand the nuances of the narrative construction in both, seeking a deeper insight, in the use of the melodrama subgenre as means of transposing a literary narrative unto film, and its possible political effects.

KEYWORDS: melodrama, Brazilian cinema, contemporary cinema, literature, female representation.
A TRANSFORMAÇ̃̃O DA NARRATIVA DO LIVRO EM MELODRAMA: ESTRUTURA E UNIVERSALIZAÇÃO TEMÁTICA

A potência transformadora e política existente numa obra artística está incluída, principalmente, em seu conteúdo. No entanto, debates acerca da potência inscrita tanto na forma quanto na produção de determinada peça artística são necessários ao se discutir a fundo tal peça. Tem-se que esta é uma visão contemporânea (e momentânea) de como abordar e construir as narrativas, mesmo que elas contem sobre épocas passadas. Duas obras recentes, o livro "A Vida Invisível" de Eurídice Gusmão, de 2016, e o filme nele inspirado, de 2019, buscam olhar para o passado brasileiro - das décadas de 1940 e 1950, respectivamente - e apresentá-lo de maneira a traçar paralelos com a atualidade. Para atingir esse objetivo, cada uma das obras utiliza técnicas narrativas distintas. No caso de "A Vida Invisível" (2019), filme de Karim Aïnouz ("Madame Satã", "O Céu de Suely"), a eficiência dessa potência narrativa vem, principalmente, da estrutura melodramática utilizada com muita propriedade. Segundo conta Aïnouz, a construção do filme se deu, também, a partir de um estudo teórico do subgênero que se denomina melodrama. Portanto, o domínio da linguagem se mostra desde antes da pré-produção e seus efeitos são vistos ao longo das duas horas de duração do filme. A estrutura deste subgênero específico difere da estrutura narrativa do livro de Martha Batalha que, não se tratando de um melodrama, perde em parte sua possibilidade de universalização da temática. A começar pelo próprio título da obra, de "A Vida Invisível" de Eurídice Gusmão, no livro para, somente, "A Vida Invisível", no filme. É claro que a adaptação de uma obra literária para uma fílmica exige muito para se capturar a essência da narrativa de uma maneira coerente, e que se trata de uma transposição propriamente dita e não de uma recriação em outra plataforma, tendo em vista que cada veículo possui suas especificidades e é impossível determinar qual é melhor ou pior. 
No entanto, tratando de questões específicas, como a universalização da temática, é possível fazer uma comparação entre as duas obras e, assim, determinar qual delas alcançou este objetivo e a quê isso se deve. Neste caso, a principal hipótese é a de que tal êxito para a assimilação do tema da tese da narrativa pelo espectador devese à utilização do melodrama e suas estruturas para cativar o público - do uso recorrente do pathos ou o apelo às emoções avassaladoras. No filme a tese proposta é a de que a estrutura social brasileira, sustentada no patriarcado, permitiu não só a invisibilidade social das mulheres ao longo das décadas até o presente, mas também demonstra que tais estruturas interferiram nas suas relações pessoais, prejudicando suas vidas enquanto cidadãs no mundo e afetando sua existência enquanto seres humanos.

Para uma análise da estrutura melodramática de "A Vida Invisível" é preciso definir o que é melodrama e seus elementos, os quais podem ou não aparecer na estrutura do filme. Neste caso, as noções pelas quais esta análise será realizada por foram investigadas e definidas por Ben Singer em seu livro "Melodrama and Modernity".

Em primeiro lugar, faz-se necessário entender que o melodrama é, essencialmente, um aglomerado de conceitos (SINGER, 2011, p. 37-58), isto é, muitas características podem ser consideradas próprias do melodrama, mas nem toda narrativa melodramática precisa dispor de todas elas para se encaixar nessa categoria. Nesse sentido, este aglomerado de noções pode ser entendido não como um gênero, mas uma estrutura complexa com subdivisões próprias criadas ao longo de mais de um século de existência, maleável como nenhuma outra estrutura narrativa. Podese até entender que "os critérios de qualificação estética [do melodrama] passam a incidir principalmente como o agrupamento se processa" (HUPPES, 2000, p. 27-32). A partir disso, entendendo que o melodrama se adapta a questões específicas de seu tempo, espaço e público, podemos analisar "A Vida Invisível" dentro da perspectiva 160 do conjunto de características que ressoam ao melodrama quando os vemos na tela — desde a estética fílmica à caracterização das personagens.

A disposição dos fatos dentro da estrutura narrativa - isto é, a sequência de fatos apresentada - é um exemplo claro de como podemos perceber a presença do melodrama na essência da história, bem como a disposição de personagens fundamentalmente bons e outros fundamentalmente ruins na trama, já que para o melodrama faz-se necessário dispor de uma moral polarizada. No entanto, o que mais salta aos olhos para a essência melodramática contida nesse produto fílmico é a ideia de ordem contida dentro da diegese, e que, com a sequência de fatos, se desestabiliza ao longo do encadeamento narrativo até alcançar seu restabelecimento - diegeticamente, anos depois da narrativa principal. Isso se dá na sequência final em que Fernanda Montenegro, que encarna Eurídice, descobre fatos que Ihe foram deliberadamente escondidos e que agora, ao serem revelados, a deixam em paz com o seu passado conturbado, e restauram, desta maneira, a ordem daquele mundo particular da narrativa.

Esta sequência, por exemplo, foi algo incluído no roteiro, pois no livro há um desfecho diferente e tais cenas finais têm justamente a função de restabelecer a ordem diegética com uma volta ao passado com elementos mantidos ocultos das personagens e do espectador - as cartas que não chegaram a tempo. Toda essa reconstituição dos acontecimentos anteriores e a reescrita da própria história faz Eurídice entrar em paz com as suas questões ao final do filme, o que traz uma sensação de alívio com um final reconfortante, mesmo que em vida as duas nunca mais tenham tornado a se ver.

Esta resolução narrativa é descrita nos estudos melodramáticos como "unhappy happy ending" (SCHATZ, 1981, p. 249). Nele, tem-se que, por mais que a resolução para as personagens seja triste, a história em si, ao ser construída de maneira coerente, 
leva à satisfação do espectador por devolver a harmonia ao mundo diegético que estava em conflito. Pode-se entender que, para o melodrama, coerência e harmonia são as principais marcas estéticas e narrativas, uma vez que sua estrutura é sempre constituída a partir de um mundo em desequilíbrio e sua função é harmonizá-lo novamente. No caso de "A Vida Invisível" isto é facilmente observável quando as revelações são feitas, pois é importante para a estrutura melodramática que a verdade seja descoberta. O fundamental para estas narrativas é a coerência interna, muito mais do que a verossimilhança externa comparada à realidade. O melodrama, portanto, realiza aqui o que realiza na maioria das vezes: não entrega um final feliz, mas um final com uma resolução aceitável dos fatos, ainda que tristes à percepção do espectador.

Esta estrutura harmônica diegética não é encontrada no livro. Nele, o sofrimento pelo qual as personagens passam não se resolve - ou seja, não é compensado ao final, e a sensação que o leitor tem é menos intensa e mais contida. A autora do livro tem outro propósito e outra tese narrativa a provar, e se utiliza de técnicas próprias para isso, construindo suas frases de modo que as maiores e mais doloridas revelações narrativas sejam apenas subentendidas pelo leitor e, assim, sua mobilização interna seja contida.

Assim, tem-se que as diferentes técnicas de engajamento do público com a narrativa tem efeitos díspares - por mais que as personagens e a história principal seja a mesma.

\section{DO LITERÁRIO AO FÍLMICO: O USO DE CARACTERÍSTICAS MELODRAMÁTICAS EM “A VIDA INVISÍVEL"}

O melodrama apresenta diversas formas de expressão, podendo ser imagética, sonora ou narrativa. Considerando-o como uma estrutura feita de excessos e 162 exageros (HUPPES, 2000), ele tende sempre a exacerbar determinado elemento fílmico e, para isso, utiliza reiterações, reforçando na trilha sonora, na encenação ou nos cenários algum aspecto diegético. Apontar esses elementos é fundamental para entender a dinâmica narrativa, simbólica e estrutural das obras que se relacionam com o melodrama pois, segundo Brooks (1995, p.1-23), "o melodrama é um sistema estético coerente", em que todos estes elementos colaboram para a harmonia e para o reforço da verossimilhança interna dentro da obra.

Considerando que a própria etimologia da palavra é derivada da junção de melos (música/melodia) e drama (ação), o uso da trilha musical, por exemplo, para a reiteração narrativa do excesso de sentimentalismo na relação entre personagens é justificável, e pode-se perceber este recurso sendo usado na cena em que Eurídice toca seu piano na audição para o conservatório. É neste momento que a memória da irmã Guida se torna mais vívida e tem-se um plano não-diegético em que as duas estão juntas. A composição deste quadro é muito interessante levando-se em conta a utilização das cores e do próprio enquadramento das irmãs, bem próximas à câmera. Entendendo que todos os elementos são reiterações uns dos outros, é possível afirmar que esta sequência do piano serve para compreender que era na música que Eurídice se encontrava com a parte que Ihe tinha sido tirada - a irmã. O fato de a competência de Eurídice como musicista ter sua base também na força de suas emoções, por si só, já seria assunto para uma pesquisa independente. Justamente por isso, ela não será aprofundada aqui.

Apesar de haver certo consenso em relação à exacerbação dos aspectos narrativos no melodrama, Singer destaca que existem outras características predominantes que podem ser observadas nas estruturas melodramáticas. São elas cinco: pathos, emoção avassaladora, moral polarizante, estrutura narrativa não-clássica e sensacionalismo. Encontradas em quase todas as narrativas a fim de servirem à construção eficaz desse 
subgênero - como ao autor designa o melodrama - nem todas precisam aparecer conjuntamente numa obra, e nem o próprio se resume a elas. Tampouco, narrativas que as apresentam em algum momento são, propriamente, melodramas. Tem-se que as adaptações, subversões e releituras do melodrama ao longo das décadas chegaram a apresentá-las de maneira mais recorrente e, por isso, Singer discorre em sua análise sobre essas manifestações, mas sem perder de vista a possibilidade da capacidade de reinvenção do melodrama, apresentando, portanto, esta ideia de "colcha de retalhos" (SINGER, 2011, apud BALTAR, 2019, p. 95-151) do subgênero. Aproveitando-se dessa amplitude de discussão, percebe-se que tais conceitos podem ser utilizados na análise da transposição do livro para o filme - e como essas cinco características predominantes são, ou não, utilizadas na estrutura.

Essencialmente, livro e filme tratam do mesmo assunto, com as mesmas histórias e mesmos personagens, e seus desencontros tendem a ser os mesmos. No entanto, pequenas escolhas narrativas — dadas pelo roteiro - mudam completamente a interpretação geral de "A Vida Invisível".

No livro, a personagem de Guida, irmã da protagonista Eurídice, casa-se com um moço rico, mas que acaba deserdado, e fica no Rio de Janeiro, mas distante da irmã e da família - e nunca mais chega a encontrar a mãe. Engravida e é abandonada pelo marido, e, a partir daí, resolve sua vida sozinha para, depois, encontrar companhia na ex-prostituta Filó, que a acolhe junto ao seu filho. Anos depois, Guida volta a entrar em contato com Eurídice, depois casa-se novamente, esquecendo seu passado ruim e mal visto. Eurídice, nesta narrativa, tenta suprir sua solidão antes da irmã voltar, ocupando seu tempo com diversos trabalhos - ela escreve um livro de receitas, costura vestidos e, no fim, escreve o "Livro da Invisibilidade", jamais lido por ninguém a não ser ela mesma. Nessa narrativa não há restabelecimento da ordem ao final e, sobretudo, não há uma relação de harmonia. Os personagens vivem com suas 164 mentiras e suas frustrações e as deixam sem resolução.

Já no filme, Guida foge com um estrangeiro e volta da Europa grávida e, em contraponto ao livro, retorna para a casa da família esperando acolhimento. É ali que o primeiro conflito e desencontro se dá. Mãe e filha se reencontram e, apesar do fato de que naquela época ter uma filha solteira e grávida fosse motivo de vergonha, a mãe a recebe de braços abertos, num plano em que quase não há falas, apenas uma representação imagética da reconciliação das duas personagens. Eurídice, já casada, não se encontra na casa dos pais e, portanto, não sabe da volta da irmã. Depois, Guida é expulsa de casa pelo pai e, quando dá à luz ao filho, abandona-o no hospital. Arrependida, retorna para buscá-lo e busca abrigo e acolhimento em Filó (personagem que permanece constante nas duas obras). Assim, Guida passa anos acreditando que Eurídice foi morar na Europa, sem saber que esta continuava no Rio de Janeiro. Anos depois, Guida encontra o pai, por acaso, em um restaurante, mas é expulsa do local antes de ver Eurídice. Em vida, as irmãs nunca mais tornam a se encontrar.

O final do filme se dá pela sequência de Eurídice já bem mais velha, com sua família visitando-a. Ao descobrir as cartas antigas que a irmã lhe enviava e que nunca chegaram (pois haviam sido escondidas por Antenor, seu marido, durante todos esses anos), Eurídice vai até o endereço do remetente e descobre se tratar de uma escola, cuja dona é neta de Guida (interpretada pela mesma atriz de Guida, Julia Stockler). Ao se revelar toda a história, recheada de mal entendidos, a personagem de Eurídice finalmente entra em paz com todo o seu passado, por ter vivido um momento de esclarecimento.

As divergências narrativas entre livro e filme começam a se ampliar a partir da metade da história. Entretanto, em ambos o principal ponto da narrativa familiar se mantém: enquanto os pares românticos estão em segundo plano, o conflito 
principal se concentra na relação das duas irmãs e seus encontros e desencontros. No entanto, esta relação no filme acontece com muito mais força, justamente pelo uso do melodrama dentro de sua estrutura. O melodrama familiar exige um conflito e uma resolução. Os desencontros ocasionados pelo acaso (ou seja, não derivados das decisões de nenhum dos personagens) são dados no destino das duas irmãs, e são os responsáveis pelo fato das duas nunca se reverem e nunca realmente terem consciência do que acontece com a outra.

No entanto, o livro apresenta uma resolução diferente, já que, não se tratando de um melodrama, não segue a estruturação de conflito e resolução. Conforme dito anteriormente, o final da narrativa literária não apresenta um desenlace harmônico: temos apenas que as duas irmãs voltaram a se encontrar e que, depois, Eurídice deixou seu livro, numa gaveta e, esquecido, nunca foi lido. Essa resolução é angustiante para o leitor, que não vê nem no reencontro nem no livro uma possibilidade de harmonização do mundo e, portanto, não é internamente satisfatório. Além disso, ao contrário do melodrama, o livro trabalha muito, na construção frasal, principalmente, com informações sublimadas, inferindo que o leitor tome conhecimento do que aconteceu e pressuponha a reação das personagens àquilo. Tornando, assim, a experiência mais distante do que é vista no filme.

Além disso, no caso do filme, a personagem de Guida é construída de modo a contrariar a protagonista dos melodramas clássicos, em que, conforme Schatz (1981), a heroína tem por maior virtude a sua virgindade e que, ao ser tomada, literal e figurativamente, por algum homem, se entrega completamente a ele, tornandose sua propriedade e perdendo sua identidade individual. Neste caso, no entanto, a personagem de Guida não se resume a esta ou aquela virtude — ao contrário, já que sua personalidade também é moldada a partir das escolhas que toma em situações adversas - tornando esta reinvenção melodramática mais complexa e interessante.
A utilização do pathos, isto é, a empatia criada pelo espectador sobre determinado personagem ou situação, é comum às duas narrativas, e no filme temos a mimese a reforçar isso. Singer (2011), ao citar Aristóteles, analisa a experiência do pathos como um tipo de sensação física intensa que é desencadeada pela percepção de uma injustiça moral contra uma vítima que não a merece. E que, além disso, num segundo momento, pode requerer uma identificação do espectador com a personagem em questão. Esta característica quando encontrada no livro, em que o leitor acompanha a personagem principal de perto, é enunciada por meio do narrador onisciente que discorre sobre os acontecimentos e sentimentos de Eurídice e, posteriormente, os de Guida também. É o que cria a sensação de angústia ao final da narrativa, já que o leitor se compadece das situações a que as personagens são submetidas, seja no abandono sofrido por Guida, seja na rotina vazia de Eurídice. Já no filme essa percepção de injustiça moral pode ser vista no momento em que o espectador toma conhecimento da gravidez de Eurídice, por exemplo. Este será seu primeiro filho, mas ela não deseja a maternidade neste momento e cogita um aborto. Até este momento do filme, a personagem havia sido construída como uma mulher com vontades próprias, o que justifica e torna plausíveis suas motivações. Mais de uma vez ela repete em cena que não quer engravidar ainda porque tem o sonho de estudar em um conservatório em Viena. Dessa maneira, o espectador é conduzido a sentir empatia pela situação de Eurídice, uma vez que já estava envolvido na trajetória da personagem.

Outro exemplo é visto na situação de Guida, que tem o filho, abandona-o e depois retorna em desespero para buscá-lo. O desamparo e a dor sentidos pela personagem são muito visuais, tanto na cena do parto quanto na sequência da volta para casa, sozinha. Aqui, o espectador também é conduzido de maneira muito próxima à personagem e percebe a assimilação de sua culpa pelo abandono do filho; esta estratégia narrativa influencia o público a se compadecer com a situação. O espectador 
sente a dor da personagem e a acompanha nessa estrada de redenção após recuperálo, testemunhando seu amor e devoção, perdoando-a pelas decisões anteriores - que podem ser interpretadas como erros - e torcendo pela resolução de seus problemas. Em "A Vida Invisível", a utilização do pathos é unicamente associada às personagens femininas.

Uma sequência importante em que podemos analisar diversos aspectos narrativos, estruturais e simbólicos, e perceber a finalidade da utilização do pathos, acontece no momento em que Eurídice faz uma descoberta sobre a suposta morte de Guida, o que leva à primeira enxurrada de revelações entre os familiares. Ao ver o nome da irmã na lápide, Eurídice se desespera. Todas as provas apontam para a sua morte. É somente quando seu pai pergunta sobre o filho que ela carregava que o retorno da irmã, anos antes, é revelado a Eurídice. Junto disso, ela descobre também que sua mãe sempre teve conhecimento destes fatos. Essa revelação muda tudo para a personagem. Ao acreditar que a irmã morreu, Eurídice desiste de ir para o conservatório, em que sonhou por muito tempo estudar, atrelando simbolicamente a irmã à música. Isso se percebe na decisão de Eurídice de atear fogo aos pertences da irmã e, depois, ao piano - seu único refúgio dentro da vida que levava como mãe e esposa. A falsa morte da irmã e a queima do piano simbolizam a mesma coisa: a perda da esperança de um escape da vida cerceada que é mostrada como única possibilidade às mulheres. E tudo isso é causado pelos desencontros não controlados por nenhuma dessas personagens. O problema destes desencontros dentro da estrutura narrativa é que, ao serem desenvolvidos paralelamente, geram resoluções que se configuram como falsas, criadas por meio de coincidências, sem que nem Eurídice e nem Guida tenham controle sobre o que lhes acontece e cerceia. Essa configuração demonstra uma estrutura narrativa não-clássica, que se opõe às narrativas clássicas por não utilizar a relação de causa/efeito.
Em contraponto ao filme, o livro não apresenta essa estrutura, já que as resoluções se dão de forma coerente à relação causa/efeito. As irmãs, por exemplo, tornam a se encontrar, e as resoluções sentimentais são apresentadas de maneira mais simples, já que os desencontros e mentiras criadas pelas personagens não são revelados, e suas vidas têm resoluções quase descomplicadas. A única inquietação de Eurídice torna a ser a da própria reflexão sobre sua vida, quando decide escrever seu Livro da Invisibilidade. No entanto, nada de grandioso muda em seus dias, e sua rotina permanece, até sua morte. Não se tem grandes reviravoltas como percebemos no filme, com as cenas de grandes revelações e que servem como pontos de virada importantes para o andamento narrativo.

A característica da emoção avassaladora é observável nas cenas de desenlace no filme, seja a encenação exacerbada dos atores na cena do cemitério em que Eurídice grita e chora com os homens que a cercam, frustrada com o conhecimento dos fatos que impediram seu reencontro com a irmã, seja na encenação contida, mas carregada de simbologia, da cena em que Eurídice ateia fogo ao piano. Percebe-se que as emoções avassaladoras estão presentes em momentos de descoberta, ou de resolução - como na sequência final, quando Eurídice descobre sobre as cartas, em que se projeta nos espectadores uma sensação de conforto e emoção advinda da resolução (o unhappy happy ending). Estas sensações estão sempre conectadas à utilização do pathos, performadas pelas personagens femininas. Esta característica não aparece no livro, uma vez que, como dito, as resoluções são mais simples e abrandadas, não se utilizando do exagero de emoções que a narrativa melodramática do filme se propõe a trabalhar.

Outro traço percebido no filme é o uso da moral polarizante muito mais reforçada do que no livro. No filme, todos os personagens masculinos são desenhados como ruins, ao passo que as mulheres se configuram como as heroínas, as personagens boas, 
por mais que cometam erros: são construídas como pessoas de bom coração, que sofrem com os infortúnios oriundos de uma sociedade masculina discriminatória, machista e misógina. É certo que as duas narrativas, tanto literária quanto fílmica, têm como mesmo propósito provar a tese de que as mulheres permanecem invisíveis e que a sociedade as cerceia de diversas formas. Tais traços sociais são tão profundos na realidade brasileira que a identificação com personagens que vivem há mais de cinquenta anos de diferença do espectador atual é imediata. Assim o filme, utilizandose dessa polarização muito clara, reforçada diegética e mimeticamente, alcança mais força na hora de provar essa tese.

Este traço não é percebido no livro, que busca outro tipo de abordagem: constrói todo o background do personagem com uma ação ruim, justificando tal ação, forçando o espectador a criar empatia mesmo pelas desavenças das protagonistas - como as vizinhas fofoqueiras que criam mentiras e perturbam a paz das protagonistas. No livro as personagens são mais esféricas. Ao não se apresentar os personagens por essa lógica de moral polarizante, não há o reforço narrativo de que o patriarcado é o causador de todas as injúrias das personagens femininas. Isso não quer dizer que esta questão não esteja sendo explanada na história do livro, apenas tem-se que não há a utilização de um recurso estrutural narrativo a fim de reafirmá-la. Esta falta de reiteração numa narrativa não melodramática diminui consideravelmente sua força e sua potência de engajamento do público.

Nesta análise, não foi considerado nenhum ponto em que o uso do sensacionalismo se fez necessário - uma vez que as duas peças comparadas se tratam de narrativas familiares, não exigindo a utilização de cenas de ação ou algo parecido. É justamente pela presença dos elementos acima analisados que o espetáculo, o exagero e o excesso são apresentados na peça fílmica.

\section{O OLHAR PÚBLICO E A ESFERA PRIVADA: PONTE PARA O MELODRAMA}

Outra perspectiva importante para pensar o melodrama é o da relação entre a esfera do olhar público versus a vida privada, como aponta Mariana Baltar (2019). Na narrativa literária, este é o aspecto que mais se aproxima do melodrama. No livro, vizinhas fofoqueiras que controlam o ir e vir das duas irmãs, em todos os momentos da história, são essenciais para essa dinâmica ser estabelecida. Este é o cerne da questão melodramática no que diz respeito à sociedade. O roteiro absorve bastante a questão da maledicência com maestria e a utiliza como ponte para a construção do melodrama, mas apresentando-a de maneira mimética. No livro, as personagens das vizinhas fofocam entre si e ditam comentários sobre a vida alheia sem nenhuma cautela. Já no filme tais personagens não existem, e o olhar público se configura nas escolhas de enquadramentos e, principalmente, na sequência em que Guida é impedida de entrar num restaurante por sua estrutura familiar não se encaixar nos padrões. Não há nenhuma fala sobre isso, mas a narrativa deixa implícito este não pertencimento.

A escolha de retirar as personagens e deixar que essa parte seja contada por meio da câmera e das situações implícitas parece, aos olhos desta análise, uma escolha inteligente do roteiro, pois normaliza tais situações, ao passo que as denuncia com maior veemência. É também um aspecto social que impede que as duas irmãs se encontrem, escancarando a diferença de classe que as distancia de todas as maneiras. O comentário aqui é, acima de tudo, sobre a estrutura da sociedade brasileira dos anos cinquenta, abrangente mesmo contando a história de um núcleo familiar muito específico. A capacidade universalizante do melodrama mostra que, embora a narrativa e os personagens possam muitas vezes parecerem simples à primeira vista, a interpretação dos fatos pode se revelar muito mais complexa. Ainda que ele tenha como característica a simplificação para facilitar a compreensão do mundo, isto não 
impede um olhar mais crítico para as situações descritas.

\section{APRENDER COM O CORAÇÃO: A PEDAGOGIA DAS SENSAÇÕES}

O melodrama, em sua característica bastante popularesca, absorve muito de cada contexto social ao longo das décadas, apropriando-se de ideais de estruturas familiares e, principalmente, adotando a moral de cada autor específico. Considerase a chegada da modernidade - entendida aqui como a consolidação da sociedade burguesa e todos os valores atrelados a ela - a primeira aparição do melodrama e, portanto, sua principal influência. Bem por isso, seus valores estéticos e narrativos são diretamente associados aos valores desta sociedade. Nas histórias melodramáticas os personagens principais podem ser pessoas reais, a partir do que descreve Peter Brooks (1995) como "a melodramatização da esfera doméstica", que apresentam questionamentos no seu cotidiano, e não nobres com dilemas fora do alcance do público. Essa abordagem do cotidiano aproxima mais obra e espectador, tornando-o mais permeável para a tese artística por se encontrar mais próxima de sua realidade. Essa característica que se enxerga no melodrama vem da necessidade da sociedade moderna de um guia moral.

Brooks explica que antes da modernidade e dos valores burgueses, havia na Europa valores medievais atrelados à lgreja Católica acerca da vida cotidiana (família, trabalho, postura perante a sociedade).Com a consolidação do Estado burguês, a moral adotada neste contexto pós-sagrado precisava ser expandida para todas as camadas sociais e a arte desempenhou seu papel de difusora, adotando uma postura pedagógica. Por isso, o melodrama clássico gira sempre em torno de uma moral e sempre tem algo a ensinar aos espectadores. Isto se dá, preliminarmente, pela simplificação do mundo, já que, em consequência deste objetivo pedagógico, o melodrama não pode admitir as ambiguidades e complexidades da realidade material. $O$ ato de polarizar 172 as histórias contadas - criando heróis e vilões, e reforçando as noções de certo e errado - promove uma explicação simplista e acessível da ordem moral de seu contexto. O que torna, portanto, a arte melodramática o novo parâmetro moral.

As estratégias para uma boa assimilação desses ensinamentos podem ser diferentes dependendo do contexto sócio-político no qual o melodrama discutido se encontra. Mariana Baltar (2019) defende que essa função da pedagogia moralizante atrelada ao melodrama tem por sua principal estratégia a pedagogia das sensações, isto é, ensinar algo a partir do excesso de emoções, como um processo de domesticação do público. Por meio desse excesso de sentimentos expostos no filme é possível entender que esse sofrimento serve a algum propósito — neste caso, à internalização da tese narrativa. Diferente da catarse aristotélica, a pedagogia das sensações não visa um treino de sentimentos à sociedade, mas uma não-contenção sentimental que é aceita e absorvida.

Em "A Vida Invisível" é possível perceber esse uso nas sequências de emoções avassaladoras, principalmente na sequência final: ao se emocionar com a resolução de Eurídice, sente-se o peso da solidão em que ela viveu por tantos anos. A tristeza transmitida é tamanha que entende-se que a única razão pela infelicidade vivida pelas personagens era a existência dessa sociedade que cerceia as mulheres em suas vidas pessoais e profissionais. Diante disso, o filme apresenta-se também como uma fértil possibilidade para a discussão da estrutura patriarcal persistente até hoje e para a sustentação do discurso de que, não importa o quanto pareça que a condição da mulher tenha mudado, as marcas dessa história ainda respingam nas mulheres de hoje da mesma maneira que afetaram suas mães e avós. 


\section{"A VIDA INVISÍVEL" DE TODAS AS MULHERES: A REITERAÇÃO DOS CICLOS E DIMENSÕES POLÍTICAS POSSÍVEIS}

Um filme utiliza linguagens muito diferentes de um livro, este centrado no verbo, pela necessidade de utilizar palavras para se fazer compreender. Num filme, no entanto, a mesma ação, sentimento ou conflito podem ser expressados sem que uma única palavra seja dita. Essa habilidade é muito instigante para a análise de uma obra e em "A Vida Invisível" não é diferente. A narrativa toda do filme volta-se à contemplação da condição da mulher branca ocidental, marcada de um cerceamento moral desde seu nascimento, e, conforme já dito, mesmo se tratando de uma narrativa ambientada nos anos cinquenta, tem muito a nos fazer refletir sobre a situação atual e nos fazer repensar sobre o quanto, de fato, as mulheres estão mais ou menos livres da estrutura patriarcal.

Na sequência final do filme, as atrizes são designadas a outros papéis. A atriz Cristina Pereira primeiro aparece encenando a mãe de Eurídice e Guida, Dona Ana, e na sequência final interpreta Cecília, filha de Eurídice. O mesmo acontece com a atriz Julia Stockler, que é Guida e sua neta, de mesmo nome. O uso das mesmas mulheres em papéis conectados sugere, em uma primeira análise, a reiteração dos ciclos entre as mulheres de uma mesma família, como se suas vidas já estivessem determinadas no momento em que nasceram. Nada a mais é esperado dessas mulheres a não ser o que já é comum a todas elas: família, filhos e, sobretudo, silêncio e invisibilidade.

Os ciclos são descritos também no livro, mas com menos força e, sobretudo, e de forma menos universalizante, pois não apresenta uma ampliação temporal que mostre a retomada desses papéis. Ao enxergar a imagem das mulheres da família se repetirem, o espectador é induzido, por essa simbologia, a refletir sobre os ciclos dentro de sua família. Entende-se, nesta análise, que a tese narrativa tem por objetivo conduzir o espectador à conclusão de que as mulheres têm uma função muito bem 174 delimitada dentro da sociedade patriarcal e que cabe unicamente a elas a quebra desses ciclos, rumo a uma verdadeira emancipação.

Se a tendência do cinema de autor dos anos 1950 e 1960 era ressaltar o divórcio entre o gênero popular e o cinema crítico, conforme propõe Ismail Xavier (2003), o melodrama permaneceu como alternativa para a intersecção das necessidades artísticas e pessoais dos autores - criando, assim, realizadores impecáveis como Sirk, Fassbinder, Almodóvar, que foram capazes de compor filmes para as massas e de maneira a serem instigantes o suficiente para se popularizarem, sem perder a carga política que se fazia necessária em cada momento e lugar. Karim Aïnouz, ao estudar tais autores, se apropria do melodrama para aproximar o cinema de gênero popular à crítica social - e o faz muito bem. O filme constrói personagens femininas complexas e busca provocar nas espectadoras uma identificação com elas, conseguindo comunicar-se com diferentes estratos sociais. A narrativa demonstra sua complexidade emocional ao passo que simplifica as condições diegéticas em que elas se dão, os esquemas sociais do mundo real e permite ao espectador apreender mais facilmente a tese que o filme busca provar.

Assim, a adesão mental à tese pela qual o espectador passa tem como objetivo levar a uma reflexão comportamental, uma vez que o uso do pathos implica em se colocar no lugar das personagens e, assim, refletir sobre a sua própria condição no mundo. Por mais que o cinema e, principalmente, o melodrama tenham a tendência de serem experiências coletivas e abrangentes - já que buscam atingir o máximo de pessoas possível — a reação a estas condições é, neste caso, individual.

Esta análise visa concluir que, se em seu surgimento o melodrama tinha a função de delimitar/tornar clara uma moral, difundindo-a socialmente, hoje sua capacidade de reinvenção pode ser reapropriada em prol de sua potência política de subverter noções sociais pré estabelecidas. Mesmo que um único filme não resulte no 
desmantelamento completo da estrutura patriarcal, ao menos ele se torna um espaço para reflexão individual que pode ser porta de entrada para uma ação organizada na sociedade e, neste caso, protagonizada por mulheres.

\section{REFERÊNCIAS}

A VIDA Invisível. Direção: Karim Aïnouz. Vitrine Filmes, 2019.

BALTAR, Mariana. Imaginação Melodramática - instâncias do privado e a pedagogia das sensações. In: BALTAR, Mariana. Realidade Lacrimosa: o melodramático no documentário brasileiro contemporâneo. Niterói: Eduff, 2019, p. 95-151.

BATALHA, Martha. A Vida Invisível de Eurídice Gusmão. São Paulo, Companhia das Letras, 2016.

BROOKS, Peter. The Melodramatic Imagination: Balzac, Henry James, Melodrama, and the Mode of Excess. New Haven/ London, Yale University Press, 1995.

HUPPES, Ivete. Melodrama: 0 gênero e sua permanência. Cotia: Ateliê Editorial, 2000.

MARTÍN-BARBERO, Jesús. Nem povo nem classes: a sociedade de massas. In: MARTíNBARBERO, Jesús. Dos meios à mediação: comunicação, cultura e hegemonia. Rio de janeiro, Editora UFRJ, 2006, p. 43 - 63

SCHATZ, Thomas. The family melodrama. In: SCHATZ, Thomas. Hollywood Genres. New York, Random House, 1981, p. 221 - 260.

SINGER, Ben. Meanings of Melodrama. In: SINGER, Ben. Melodrama and Modernity. New York: Columbia University Press, 2011, p. 37-58.

XAVIER, Ismail. Melodrama, ou a sedução da moral negociada. In: XAVIER, Ismail. $O$ olhar e a cena: melodrama, Hollywood, Cinema Novo, Nelson Rodrigues. São Paulo, Cosac e Naify, 2003, p.85-99. 